\title{
Incorporating Individual Teachings (aka Individual Contact Teaching Methods) into a Sustainable Landscaping Extension Plan of Work and Report of Accomplishments ${ }^{1}$
}

\author{
Laura Sanagorski
}

\section{Introduction}

Many horticultural Extension professionals conduct numerous consulting phone calls, send e-mails, visit offices, conduct research, and visit landscapes to solve horticultural problems and concerns. Although many Extension faculty members are initially unaware that they educate clients when providing these services, these activities should be considered major educational methods. The activities should also be planned by Extension faculty and reported in an Extension plan of work (POW) and in their annual report of accomplishments (ROA).

Even though quantifying the impacts of this educational methodology can be challenging, the impacts are truly important because these services are valuable parts of Extension programming. An Extension program refers to a collection of educational activities that seek to achieve some specified outcomes among a particular audience (Israel, Harder, \& Brodeur, 2012). The purpose of this article is to describe possible uses of individual teachings in an Extension faculty member's plan of work, suggest possible programming objectives, and recommend methods of evaluating these educational activities.

Throughout this article, landscape-site visits, e-mail and phone call consultations, and office visits will be collectively referred to as Individual Contact Teaching Methods (Seevers \& Graham, 2012). These personalized, educational opportunities allow the learner to seek clarification, incorporate new material into their existing knowledge, and develop a deeper understanding of information that is tailored to their needs (Guion, 2006). Beyond knowledge, the learner may acquire new capabilities, skills, or goals. As a result of educational programming, an Extension professional will likely see his or her clients make changes in patterns. County faculty working in environmental horticulture may find that the changes include: reduction of landscape water overuse, adoption of the "right plant, right place" concept, and increased ability to properly identify pests. When planned thoughtfully, communicated clearly, and evaluated appropriately, Individual Contact Teaching can become a substantial part of an Extension program.

\section{The Extension Report of}

\section{Accomplishments and Plan of Work}

In Florida, Extension program planning includes documenting planned activities and communicating results through an annual Report of Accomplishments (ROA) and a Plan of Work (POW). These two documents are combined to create "the only official report that encompasses [an Extension professional's] complete

1. This document is AEC493 (formerly WC157), one of a series of the Agricultural Education and Communication Department, UF/IFAS Extension. Original publication date November 2013. Visit the EDIS website at http://edis.ifas.ufl.edu.

2. Laura Sanagorski, assistant professor, Department of Agricultural Education and Communication; UF/IFAS Extension Gainesville, FL 32611. 
annual body of work" (University of Florida, 2011). Thus, thoughtful consideration on the report's content is essential. The Extension ROA/POW includes several sections that are organized in the following order: Situation, Program Objectives, Educational Methods and Activities, Outcomes and Impacts, and Success Stories.

\section{Incorporating Individual Contact Teaching into the Extension Plan of Work}

Objectives can be set and reevaluated regularly to meet the needs of one's programs and clientele. Individual Contact Teaching objectives can be communicated under the "Program Objectives" part of the "Extension Programs" section in a ROA/POW. According to Diehl and Galindo-Gonzalez (2012), Extension objectives should be Specific, Measurable, Achievable, Relevant, and Time-Bound (SMART). Table 1 presents several possible program outcomes and their potential corresponding outcomes.

Planned Individual Contact Teaching Methods can be communicated under the "Educational Methods and Activities" part of the "Extension Programs" section (University of Florida, 2013). The following is an example of text that can be used to describe these activities:

\section{Example of Individual Contact Teaching Activities Communicated in the Educational Methods and Activities Section}

This Extension program offers many one-on-one consultations through in-office sessions, landscape-site visits, telephone calls, and e-mails. The agent is often asked to diagnose landscape disorders and make recommendations for management options. Frequently, cryptic turf decline and tree disorders are the reasons for the requested consultation. The agent regularly identifies pests and diseases, but he/she often determines that the cause of a problem derives from inappropriate cultural practices, such as overwatering or over-fertilizing. These cultural practices contribute to runoff and nonpoint source pollution, which affect local ground and surface waters. In many cases, a change in cultural practices improves the health of the client's landscape and reduces the environmental impact. Individual Contact Teaching Methods support Extension clients' decision-making, while reducing negative cultural practices. Common topics include: 1) troubleshooting and improving fertilization and irrigation plans; 2) identifying disease and recommending cultural management.
In 2013, the agent personally conducted site visits, e-mails, phone calls, office consultations, and provided research-based, follow-up documentation and recommendations.

\section{Incorporating Individual Contact Teaching into the Extension Report of Accomplishments}

Evaluating outcomes and impacts from Extension programming generates accountability and provides the opportunity to redirect programs to better serve Extension clients (Lamm, Israel, Diehl, \& Harder, 2011). There are numerous evaluation levels, and multiple levels should be used to measure an Extension program's outcomes and impacts.

Individual Contact Teaching objectives may address different types of short- to medium-term outcomes, such as participation, Knowledge Attitudes Skills Aspirations (KASA), and reactions (Harder, 2013). They may also include long-term results, such as practices and Social Economic Environmental (SEE) conditions and impacts (Harder, 2013). Extension professionals are encouraged to incorporate practices and SEE conditions, which are the strongest levels of program results, into their evaluation plans (Harder, 2013; Lamm et al., 2011). Thus, a focus on behavioral and SEE changes made by Individual Contact Teaching activities would strengthen a ROA/POW.

The following is an example of objectives and outcomes that can be used to describe Individual Contact Teaching Methods as part of an Extension program.

\section{Suggested Methods of Evaluation}

As the annual ROA/POW is a critical part of the accountability process (University of Florida, 2011), it is also important to measure outcomes and impacts thoughtfully and thoroughly. Evaluation of Individual Contact Teaching Methods can generate qualitative data, such as reasoning to adopt a practice or feelings about a topic, and quantitative data, such as number of participants, gallons of water saved, or knowledge gained. The following are suggested tools that can be used to support the evaluation of Individual Contact Teaching Methods.

- Site visit or diagnosis request forms - Consider using a site visit or diagnosis request form for clients to initiate an Individual Contact Teaching event. This form can be paper or electronic, and it can collect the client's contact information, the type of problem, and current cultural practices used (irrigation time of day, irrigation frequency and depth, type of fertilizer used, annual 
Table 1. Example program objectives and outcomes for individual contact teaching methods

1. (Example Participation Objective) Annually, 100 green industry professionals will participate in Individual Contact Teaching, as measured by documenting site visits and office consultations. a. (Example Participation Outcome) 122 green industry professionals participated in Individual Contact Teaching in 2012 as measured by activity documentation.

2. (Example Reactions Objective) Annually, 80\% of participants in Individual Contact Teaching education will report their satisfaction with the service they receive, as measured by an exit survey taken at the conclusion of the consultation.

a. (Example Reactions Objective) $93 \%$ ( $n=113$ ) of Individual Contact Teaching education participants in 2013 reported satisfaction with the service they received, as measured by an exit survey taken at the conclusion of the consultation.

3. (Example KASA Objective) Annually, $75 \%$ of homeowners participating in Individual Contact Teaching education will report plans to adopt one new best management practice, as measured by an exit survey taken at the conclusion of the consultation.

a. (Example KASA Outcome) $89 \%(n=109)$ of homeowners participating in Individual Contact Teaching education reported plans to adopt one new best management practice, as measured by an exit survey taken at the conclusion of the consultation.

4. (Example Practices Objective) Annually, 50\% of green industry professionals participating in Individual Contact Teaching education will report the adoption of a new best management practice, as measured by taking a six-month follow-up survey.

a. (Example Practices Outcome) $61 \%(n=74)$ of green industry professionals participating in Individual Contact Teaching education reported the adoption of a new best management practice, as measured by taking a six-month follow-up survey. The most common practices adopted include: reducing landscape irrigation usage ( $n=43)$ and changing fertilizer products $(n=29)$ to meet UF/IFAS recommendations.

5. (Example SEE Conditions Objective) Annually, $25 \%$ of homeowners association board members participating in Individual Contact Teaching education will report a reduction in fertilizer or pesticide costs as a result of the consultation, as measured by taking a nine-month, follow-up survey.

a. (Example SEE Conditions Impact) $12 \%(n=15)$ of homeowners association board members participating in Individual Contact Teaching education reported a reduction in fertilizer or pesticide costs as a result of the consultation, as measured by taking a nine-month follow-up survey. pest-control budget, etc.). The form can also be used to assist in scheduling and documenting the recommendations made. It may also collect useful contact information to determine if behavior changes have resulted in the future. Throughout time, this information can provide a detailed picture of the major issues and solutions provided through this service. The information can also be used to estimate impacts, regarding water, fertilizer, or money saved. For example, if a homeowners' association irrigates three times per week at the time they request a consulting site visit, the agent may recommend reducing the frequency to two times per week. If the agent confirms the recommendations are being followed in the future, the homeowners' association could reduce their landscape water usage by an estimated $30 \%$ as a result of the site visit.

- Documentation of efforts - A personal documentation system that collects numbers and types of consulting, educational events can provide a rich picture of these occurrences at the end of one year. Types of issues discussed, problems solved, and recommendations made should be recorded, as well as clients' contact information for future evaluation methods. A written journal or logbook, electronic calendar, or spreadsheet may support documentation of Individual Contact Teaching Methods.

- Documentation of observations - Post-education observations can be useful tools in measuring outcomes. For example, an Extension professional may frequently recommend that homeowners' associations manage grass clippings, so the clippings remain on the landscape and not reach the streets and storm drains. On future dates, the professional may then conduct drive-by observations to determine whether the recommendations are being followed. Observation can be especially useful when findings are well-documented. Documentation may be written, electronically recorded, and photographed, and it may be combined with documentation of efforts.

- Surveys - Depending on the type of outcome being measured, surveys can be conducted with Individual Contact Teaching participants on the day of or after the consultation. Surveys may be conducted to collect reactions and changes in KASA, practices, and SEE conditions, and they can be done verbally (in person or by telephone), by e-mail, or by postal mail.

- Publicly Available Data - Publicly available data may provide an indication of changes in SEE conditions, such as income or environmental indicators throughout time (Harder, 2013). For example, focused education related to minimizing environmental impacts through horticultural practices in a particular watershed could 
result in improving the local water quality. The local water management authority's water-quality reports could be used to quantify changes in the local environment.

\section{Conclusion}

Individual Contact Teaching should be considered major educational methods and activities and should be reported in Extension professionals' ROA/POW. Communicating the planned activities and quantifying the impacts made using this educational methodology can be challenging, but they are important to both program planning and overall accountability. This article emphasized the importance of including Individual Contact Teaching Methods in the POW and suggested potential program objectives and methods of evaluation for use in the ROA.

\section{References and Further Reading}

Diehl, D. C., \& Galindo-Gonzalez, S. (2012). Get SMART: Improve your Extension objectives (FCS6018). Gainesville, Florida. UF/IFAS. Retrieved from http://edis.ifas.ufl.edu/ fy 1327

Guion, L. A. (2006). Educational methods for Extension programs (FCS6013). Gainesville, Florida. UF/IFAS.

Retrieved from http://edis.ifas.ufl.edu/fy399

Harder, A. (2013). Using the TOP model to measure program performance: A pocket reference (2nd ed.) (WC092). Gainesville, Florida. UF/IFAS. Retrieved from http://edis.ifas.ufl. edu/wc092
Israel, G. D., Harder, A., \& Brodeur, C. W. (2012). What is an Extension program? (WC108). Gainesville, Florida. UF/ IFAS. Retrieved from http://edis.ifas.ufl.edu/wc108

Lamm, A. J., Israel, G. D., Diehl, D., \& Harder, A. (2011). Evaluating extension programs (WC109). Gainesville, Florida. UF/IFAS. Retrieved from http://edis.ifas.ufl.edu/ wc109

Seevers, B., \& Graham, D. (2012). Education through cooperative extension (3rd ed.). Fayetteville, AR: University of Arkansas.

University of Florida. (2011). Policy concerning annual Reports of Accomplishments and Plans of Work (ROA/POW) submission deadline and quality for UF/IFAS Extension county faculty. Retrieved from: http://ded.ifas.ufl.edu

University of Florida. (2013). Detailed guidelines for the 2013 ROA and 2014 POW. Retrieved from: http://ded.ifas. ufl.edu 